\title{
MODEL PROBLEM BASED LEARNING TIPE CPS DAN SSCS UNTUK MENINGKATKAN KEMAMPUAN BERPIKIR KRITIS SISWA
}

\author{
Apriyanti', Yuyu Yuhana ${ }^{2}$, Abdul Fatah ${ }^{3}$ \\ ${ }^{123}$ Universitas Sultan Ageng Tirtayasa, Jl. Raya Jakarta, Kota Serang, Banten. (0254) 280330, Indonesia \\ e-mail: alyanti14@gmail.com
}

\begin{abstract}
Abstrak
Penelitian ini bertujuan untuk mengetahui model pembelajaran mana yang lebih baik untuk meningkatan kemampuan berpikir kritis siswa, antara siswa yang menggunakan model problem based learning tipe CPS dan SSCS. Populasi penelitian ini adalah seluruh siswa SMAN 6 Pandeglang, sampel dipilih 2 kelas, dalam menentukan kelas eksperimen 1 dan 2 dilakukan secara purposive sampling. Tes berupa 5 soal uraian yang sesuai dengan indikator kemampuan berpikir krtis. Pretes dilakukan sebagai tes kemampuan awal sebelum perlakuan menggunakan model problem based learning tipe CPS dan SSCS. Postes dilakukan setelah diberikan perlakuan menggunakan model problem based learning tipe CPS dan SSCS. Hasil yang diperoleh setelah proses pembelajaran menggunakan model problem based learning tipe CPS dan SSCS dapat disimpulkan bahwa kemampuan berpikir krtis siswa yang menggunakan model problem based learning tipe SSCS lebih baik dari pada kemampuan berpikir kritis siswa yangn menggunakan model problem based learning tipe CPS.
\end{abstract}

Kata Kunci: Model Problem Based Learning Tipe CPS, Model Problem Based Learning Tipe SSCS, Kemampuan Berpikir Kritis.

\begin{abstract}
This study aims to find out which learning model is better for improving students' critical thinking skills, among students who use the CPS type and SSCS type of problem-based learning model. The population of this study was all students of SMAN 6 Pandeglang, 2 classes was chosen as the sample, in determining the experimental class 1 and 2 it was done by purposive sampling. The test is in the form of 5 description questions in accordance with the indicator of thinking ability. Pretest was performed as an initial ability test before treatment using the CPS type and SSCS type of problem-based learning model. Posttest were carried out after the treatment of using the CPS type and SSCS type problem-based learning model. The results obtained after the learning process using the CPS type and SSCS type of problem-based learning model can be concluded that students' thinking skills using the SSCS type problem-based learning model are better than students' critical thinking abilities using CPS type of problem-based learning models.
\end{abstract}

Keywords: CPS Type of Problem Based Learning Model, SSCS type of Problem Based Learning Model, Critical Thinking Ability.

\section{PENDAHULUAN}

Peningkatan sumber daya manusia di Indonesia diawalai dari proses pendidikan yang baik, salah satu Salah satu cara dalam upaya meningkatkan sumber daya manusia yaitu dengan peningkatan pendidikan.Dalam Undang-Undang Republik Indonesia Nomor 20 tahun 2003 tentang Sistem Pendidikan Nasional dijelaskan bahwa "Pendidikan adalah usaha sadar dan terencana untuk mewujudkan suasana belajar dan proses pembelajaran agar peserta didik secara aktif mengembangkan potensi dirinya untuk memiliki kekuatan spiritual keagamaan, pengendalian diri, kepribadian, kecerdasan, ahlak mulia, serta keterampilan yang diperlukan dirinya, masyarakat, bangsa dan Negara" (Permendikbud, 2013:1). 
Matematika juga diartikan sebagai mata pelajaran yang digunakan untuk mengembangkan cara berpikir. Artinya, melalui pembelajaran matematika kemampuan memecahkan masalah, bernalar dan berkomunikasi, serta kemampuan berpikir kreatif dan inovatif akan berkembang. Pendidikan matematika yang diberikan di sekolah dapat memberikan sumbangan yang penting bagi siswa dalam mengembangkan kemampuan untuk mencapai tujuan pendidikan. Salah satu kemampuan yang harus dimiliki siswa yang terkait dengan matematika yaitu dalam kemampuan berpikir kritis matematika.

Upaya memfasilitasi agar kemampuan berpikir kritis siswa berkembang menjadi sangat penting, mengingat beberapa hasil penelitian masih mengidentifikasi rendahnya kemampuan berpikir kritis siswa Indonesia. Hasil penelitian Suryanto dan Somerset (Zulkardi, 2001) terdapat 16 Sekolah Lanjutan tingkat pertama pada beberapa provinsi di Indonesia menunjukkan hasil tes mata pelajaran matematika sangat rendah, utamanya pada soal cerita matematika (aplikasi matematika). Kemampuan aplikasi merupakan bagian dari domain kognitif yang lebih rendah dari pada kemampuan analisis, sintesis, dan evaluasi. Ketiga kemampuan tersebut digolongkan oleh Bloom (Duron, dkk., 2006) dalam kemampuan berpikir kritis.

Hasil penelitian Priatna (2003) menunjukan bahwa kemampuan penalaran siswa SMP di kota Bandung masih belum memuaskan, yaitu hanya mencapai sekitar $49 \%$ dan $50 \%$ dari skor ideal. Selanjutnya Suryadi (fachrurazi: 2011) menemukan bahwa siswa kelas dua SMP di kota dan kabupaten Bandung mengalami kesulitan dalam kemampuan mengajukan argumentasi, menerapkan konsep yang relevan, serta menemukan pola bentuk umum (kemampuan induksi). Hal ini menunjukkan rendahnya kemampuanberpikir kritis siswa, karena menurut Krulik dan Rudnick (Kurniawati, dkk. 2013) bahwa penalaran mencakup berpikir dasar (basic thinking), berpikir kritis (critical thinking), dan berpikir kreatif (creative thinking).

Dari kemampuan berpikir kritis siswa yang masih rendah dan menyadari akan pentingnya hal tersebut. Guru diharapkan dalam mengupayakan dengan menerapakan model pembelajaran yang mampu meningkatkan kemampuan berpikir kritis siswa, selain itu guru memberikan kesempatan dan mendorong kepada siswa untuk melatih kemampuan berpikir kritis, seperti memberikan permasalah-permasalah kepada siswa dan latihan soal yg bervariasi sehingga guru bisa melihat perkembangan kemampuan berpikir kritis siswa.

Model pembelajaran yang dapat diterapkan adalah model pembelajaran yang berfokus pada kemampuan berpikir kritis. Meodel pembelajaran tersebut adalah model Problem Based Model Problem Based Learning Tipe CPS dan SSCS untuk Meningkatkan Kemampuan Berpikir Kritis 
Learning (PBL). Dalam penelitian ini model Problem Based learning (PBL) yang digunakan adalah Problem BasedLearning yang mempunyai dua tipe yaitu tipe Creative Problem Solving (CPS) dan Search, Solve, Create, Share (SSCS), yang dirancang agar siswa dapat berpikir kritis dan memiliki kemandirian dalam belajar. Karena kemampuan berpikir kritis dapat berkembang melalui proses belajar mandiri.

\section{METODE PENELITIAN}

Penelitian ini menggunakan metode penelitian quasi, desain penelitian yang digunakan adalah matching pretest-posttest comparison grup design (Sukmadinata, 2011: 208). Subyek penelitian ini adalah seluruh siswa kelas XI SMAN 6 Pandeglang dan kelas yang digunakan adalah sebanyak 2 kelas, yaitu kelas eksperimen 1 dan kelas eksperimen 2. Dalam menentukan kelas eksperimen 1 dan 2 dilakukan secara purposive sampling. Menurut (Sugiyono, 2010:124) Sampling purposive adalah teknik penentuan sampel dengan pertimbangan tertentu.

Penelitian ini dibagi menjadi 3 tahapan, yaitu tahapan yang pertama adalah tahap persiapan, tahapan yang kedua adalah tahap pelaksanaan dan tahapan yang ketiga adalah tahap analisis.Teknik pengumpulan dalam data ini adalah menggunakan tes.Tes kemampuan berpikir kritis terdiri dari tes awal (Pretes) dan tes akhir (Postes).Untuk mengukur kemampuan berpikir kritis matematis siswa yang terdiri dari mengidentifikasi dan menjastifikasi konsep, menggeneralisasi, menganalisis alogoritma, memecahkan masalah.Pedmoan kriteria pensekoran menggunakan rubrik skor Facione yang memodifikasi (Ratnaningsih, 2013) dan dalam penelitian ini menggunakan pedoman penskoran menurut (Hasratuddin, 2010).Setelah diberikan perlakuan, peningkatan yang diukur adalah untuk melihat pengkatan kemampuan berpikir kritis dan untuk mengetahui model mana yang lebih baik untuk meningkatkan kemampuan berpikir kritis di kedua kelas eksperimen tersebut.

\section{HASIL DAN PEMBAHASAN}

Penelitian yang telah dilakukan untuk menganalisis pengaruh model problem based learning Tipe CPS dan SSCS untuk meningkatkan kemampuan berpikir kritis siswa. Data kemampuan berpikir kritis diukur berdasarkan peningkatan $n$-gain pada tiap kelas, baik kelas eksperimen 1 yang menggunakan model problem based learning tipe CPS dan kelas eksperimen 2 yang menggunakan model problem based learning tipe SSCS. Sebelum melihat peningkatannya, maka perlu dilihat kemampuan awal kedua kelas tersebut, karena untuk 
membandingkan harus kemampuan awalnya sama atau tidak jauh berbeda. Maka dapat dilihat pada hasil statistik deskripstif data skor pretes berpikir kritis pada Tabel 1 .

Tabel 1. Data skor pretes berpikir kritis

\begin{tabular}{|c|c|c|c|c|c|c|c|c|c|}
\hline \multirow[b]{3}{*}{ Kategori } & \multirow[b]{3}{*}{ Stat } & \multicolumn{8}{|c|}{ Kelas Dengan Pembelajaran } \\
\hline & & \multicolumn{4}{|c|}{ PBL Tipe CPS } & \multicolumn{4}{|c|}{ PBL Tipe SSCS } \\
\hline & & Pretest & Postes & (g) & $\mathbf{n}$ & Pretest & Postes & (g) & $\mathbf{n}$ \\
\hline \multirow{4}{*}{$\begin{array}{c}\text { Keseluruhan } \\
\text { Siswa }\end{array}$} & $X_{\max }$ & 4 & 18 & 0,88 & \multirow{4}{*}{31} & 6 & 18 & 0,86 & \multirow{4}{*}{33} \\
\hline & $X_{\min }$ & 11 & 14 & 0,33 & & 8 & 13 & 0,42 & \\
\hline & $\bar{X}$ & 7,77 & 16,19 & 0,67 & & 7,70 & 16,73 & 0,73 & \\
\hline & $\mathrm{s}$ & 2,31 & 1,42 & 0,15 & & 2,01 & 1,15 & 0,11 & \\
\hline
\end{tabular}

Skor Maksimal Ideal: 20 dan $N$-gain Maksimal Ideal = 1

Ditinjau berdasarkan keseluruhan siswa selisih perolehan pretes antara kelas eksperimen 1 yang menggunakan model PBL Tipe CPS dan eksperimen 2 yang menggunakan model PBL tipe SSCS adalah 0,07 dengan diungguli siswa kelas eksperimen 1 dengan menggunakan model PBL tipe CPS. Begitu juga pada kelas eksperimen 2 menggunakan model PBL Tipe SSCS lebih tinggi dari kelas eksperimen 2 menggunakan model PBL Tipe SSCS dengan selisih 0,54. Simpangan baku skor postes kelas eksperimen 1 memperoleh dengan menggunakan model PBL tipe CPS memperoleh 1,42 dan kelas eksperimen 2 menggunakan model PBL Tipe SSCS memperoleh 1,15, artinya sebaraan ratarata hitung skor postes kelas eksperimen 1 memperoleh dengan menggunakan model PBL tipe CPS lebih bervariasi dari pada kelas eksperimen 2 menggunakan model PBL Tipe SSCS. Dapat disimpulakan bahwa dari data diatas, perbedaan kedua kelas tersebut tidak teralalu signifikan untuk kemampuan awalnya.

Tujuan dari penelitian ini mengetahui model pembelajaran mana yang lebih baik untuk meningkatkan kemampuan berpikir kritis siswa. Adapun pembahasannya adalah sebagai berikut:

Hipotesis statistik untuk menguji hipotesis penelitian. Hasil penghitungan diperoleh asymp.sig (2-tailed) 0,168. Nilai tersebut lebih besar dari 0,05, sehingga $\mathrm{H}_{0}$ diterima, ini berarti hipotesis ditolak.

Perhitungan data $n$-gain kemampuan berpikir kritis dengan uji dua pihak, karena data tidak normal maka menggunakan uji non-parametrik yaitu uji Mann-Whitney berbatu aplikasi IBM SPSS versi 22. Hasil pengujian hipotesis disajikan pada Tabel 2. 
Tabel 2. Hasil Uji Perbedaan N-gain Kemampuan Berpikir Kritis Secara Keseluruhan Siswa

\begin{tabular}{|c|c|c|c|}
\hline Statistik & Nilai & Keterangan & Kesimpulan \\
\hline Mann Whiney $U$ & 409 & & \\
\hline $\mathrm{Z}$ & -1.379 & $\mathrm{H}_{0}$ diterima & Hipotesis 1 ditolak \\
\hline Asymp.sig (2-tailed) & 0.168 & & \\
\hline
\end{tabular}

Hasil uji perbedaan rata-rata memperoleh nilai asymp.sig (2-tailed) sebesar 0,168 lebih besar dari 0,05. Hal ini menunjukan hipotesis nol diterima, sehingga dapat disimpulkan bahwa rata-rata $n$-gain kemampuan berpikir kritis kelompok siswa yang menggunakan model Problem Based Learning tipe CPS lebih kecil dari pada siswa yang menggunakan model Problem Based Learning tipe SSCS.

\section{SIMPULAN DAN SARAN}

Berdasarkan rumusan masalah, hasil penelitian dan pembahasan terhadap hasil-hasil penelitian yang diuraikan pada bab sebelumnya, diperoleh kesimpulan dan saran dari peneliti ini. Berikut kesimpulan dan saran dari peneliti ini.

Peningkatan kemampuan berpikir kritis tidak terdapat perbedaan antara kelompok siswa yang menggunakan model Problem Based Learning tipe CPS dengan siswa yang menggunakan model Problem Based Learning tipe SSCS. Selain itu, peningkatan kemampuan berpikir kritis yang mendapatan model pembelajaran Problem Based Learning tipe CPS dengan siswa yang menggunakan model Problem Based Learning tipe SSCS diperoleh sebagai berikut:

Peningkatan kemampuan berpikir kritis siswa yang menggunakan model PBL Tipe CPS lebih kecil dengan siswa yang menggunakan model Problem Based Learning tipe SSCS. Maka dapat disimpulkan bahwa model problem based learning tipe SSCS lebih baik dari model problem based learning tipe CPS.

\section{DAFTAR PUSTAKA}

Bloom, Benyamin S. (1979). Taxonomy of Educational Objectives (The Clasification of Educational Goals) Handbook 1 Cognitive Domain. London: Logman Group Ltd.

Fahrurazi. (2011). Penerapan Pembelajaran Berbasis Masalah Untuk Meningkatkan Kemampuan Berpikir Kritis dan Komunikasi Matematis Siswa Sekolah Dasar. [Online]. Tersedia: file://C:/Users/Apriyanti/Download/sumber/8-Fachrurazi.pdf. 
Hasratuddin, (2010). Meningkatkan Kemampuan Berpikir Kritis dan Kecerdasan Emosional Siswa SMP Melalui Pendekatan Matematika Realistik. Bnadung: Yayasan Nuansa Cendia.

Hendriana, Heris, dkk. (2017). Hard Skill dan Soft Skill Matematika Siswa. Bandung: Refika Aditama.

Kadir. (2015). Statistika Terapan Konsep, Contoh dan Analisis Data Dengan Program SPSS/Lisrel Dalam Penelitian. Jakarta: PT. RAJA GRAPINDO PERSADA.

Kemendikbud. (2013). Permendikbud No. 81A tentang Implementasi Kurikulum.. Jakarta: Kementerian Pendidikan dan Kebudayaan.

Kurniawati, I. D, Wartono, M. Diantoro. (2013). Pengaruh Pembelajaran Inkuiri Terbimbing Integrasi Peer Intruction Terhadap Penguasaan Konsep dan Kemampuan Berpikir Kritis Siswa.Jurnal Pendidikan Fisika Indonesia.[Online].Tersedia http://journal.unnes.ac.id/nju/index.php/jpfi.

Nazir, M. (2014). Metode Penelitian. Bogor. Ghalia Indonesia.

Priatna, N. (2003). Kemampuan Penalaran dan Pemahaman Matematika Siswa Kelas III SLTP di Kota Bandung. Disertasi Bandung: SPs UPI.

Ratnaningsih, (2013). Penerapan Model Pembelajaran Kontekstual Dalam Upaya Meningkatkan Kemampuan Berpikir Kritis dan Kreatif Matematika Serta Kemandirian Belajar Siswa Sekolah Menengah Atas Ditinjau Dari Level Sekolah dan Pengetahuan Awal Matematika Siswa. Disertasi: Bandung: SPSS UPI.

Sugiyono, (2010). Metode Penelitian Pendidikan. Bandung: CV. Alfabeta.

Sukmadinata. (2011). Metode Penelitian Pendidikan. Bandung: Remaja Rasdakarya.

Zulkardi. (2001). Realistic Matematics Education (RME). Teori. Contoh Pembelajaran dan Taman Belajar di Internet. Makalah: UPI Bandung. 